Article

\title{
Nanoantioxidant-Based Silica Particles as Flavonoid Carrier for Drug Delivery Applications
}

\author{
Francisco Arriagada $1, * \mathbb{C}$, Germán Günther ${ }^{2} \mathbb{D}$ and Javier Morales ${ }^{2, *}$ \\ 1 Instituto de Farmacia, Facultad de Ciencias, Universidad Austral de Chile, 5110033 Valdivia, Chile \\ 2 Facultad de Ciencias Químicas y Farmacéuticas, Universidad de Chile, 8380494 Santiago, Chile; \\ ggunther@ciq.uchile.cl \\ * Correspondence: francisco.arriagada@uach.cl (F.A.); javiermv@ciq.uchile.cl (J.M.); Tel.: +56-63-222-1308 \\ (F.A.); +56-2-2978-1630 (J.M.)
}

Received: 7 February 2020; Accepted: 24 March 2020; Published: 26 March 2020

\begin{abstract}
Nanosystems used in pharmaceutical formulations have shown promising results in enhancing the administration of drugs of difficult formulations. In particular, porous silica nanoparticles have demonstrated excellent properties for application in biological systems; however, there are still several challenges related to the development of more effective and biocompatible materials. An interesting approach to enhance these nanomaterials has been the development of nanoantioxidant carriers. In this work, a hybrid nanoantioxidant carrier based on porous silica nanoplatform with rosmarinic acid antioxidant immobilized on its surface were developed and characterized. Techniques such as dynamic light scattering (DLS), zeta potential, transmission electron microscopy (TEM), $\mathrm{N}_{2}$ adsorption-desorption measurements, differential scanning calorimetry (DSC), Fourier transform-infrared spectroscopy (FT-IR), and 2,2-diphenyl-1-picrylhydrazyl (DPPH ${ }^{\bullet}$ ) assay were used to characterize and evaluate the antioxidant activity of nanocarriers. In addition, drug release profile was evaluated using two biorelevant media. The antioxidant activity of rosmarinic acid was maintained, suggesting the correct disposition of the moiety. Kinetic studies reveal that more morin is released in the simulated intestinal fluid than in the gastric one, while an anomalous non-Fickian release mechanism was observed. These results suggest a promising antioxidant nanocarrier suitable for future application in drug delivery.
\end{abstract}

Keywords: drug delivery; flavonoid; silica nanoparticles; nanocarrier; nanoantioxidant; morin; rosmarinic acid

\section{Introduction}

Great advancements in the area of nanomaterials have brought about opportunities to improve various processes in fields related to engineering, food industry, biomedicine, and the pharmaceutical industry, among others [1-3]. In particular, nanosystems used in pharmaceutical formulations, biomedical devices, or in theranostics have shown promising results in enhancing the administration of drugs of difficult formulations, decrease in therapy time, and early diagnosis of diseases [4]. In this context, porous silica nanoparticles have been studied as drug delivery systems (DDS) in the last two decades [5]. However, despite its excellent properties, such as its biocompatibility, high specific surface area and versatility on its surface functionalization, several challenges remain. Some of them are related to toxicity in certain tissues, clinical translation, industrial scaling, and optimization in specific drug delivery in the desired therapeutic target, in order to be incorporated as pharmaceutical products [6-9]. To overcome some of these drawbacks, bio-inspired, bio-mimetic, and smart materials, among others, have been developed [10-12]. An emerging strategy has been the development of systems called nanoantioxidants $[13,14]$. These systems are nanoparticles with intrinsic antioxidant 
activity and/or antioxidant-functionalized nanoparticles, in order to stabilize or improve the antioxidant activity, and produce materials with synergistic effects and more biocompatible, with applications as pharmaceutical excipients, food packaging or pharmaceutical carriers [15-17]. A relatively simple way to develop a polyphenolic layer on nanoparticles surface is by physical adsorption. Nonetheless, in this manner, the antioxidant molecule could undergo easy oxidation or polymerization, e.g., polyphenols browning, which restricts its lifetime; in addition, unwanted desorption and undesirable interaction could reduce its antioxidant function [16,17]. Therefore, the metal-phenolic networks approach [18] or covalent immobilization could overcome these drawbacks, generating a better pharmaceutical excipient (for non-porous particles) or, in the case of carrier particles, a better pharmaceutical vehicle. The latter ones, in general, are hybrid materials inspired by the carrier properties of inorganic nanoplatforms with functionalized antioxidants on the surface. Nevertheless, reports in the literature on its use as vehicles for drug delivery are limited. For example, Massaro and co-workers developed a synergistic nanoantioxidant based on the grafted of trolox on the surface of halloysite nanotubes loaded with quercetin [19]. In another study, Ebabe Elle and co-workers reported a novel carrier using mesoporous silica nanoparticles functionalized with caffeic acid or rutin, showing that the level of ROS generated by the bare silica nanoparticles decreases with the immobilization of these polyphenols on the surface of nanoparticles [20]. Arriagada and colleagues developed core-shell mesoporous silica nanospheres functionalized with caffeic acid, showing the ability of the antioxidant nanomaterial to protect oxidation-sensitive molecules [21]. These types of nanoantioxidant attempt to generate more effective and biocompatible materials, not only by using natural polyphenols to coat nanoparticles but also by releasing biomolecules with potential pharmacological activity, such as flavonoids.

Morin $\left(3,5,7,2^{\prime}, 4^{\prime}\right.$-pentahydroxyflavone) $(\mathrm{MH})$ is a flavonoid that commonly occurs in various fruits and vegetables of the Moraceae family [22,23], which has been shown a remarkable antioxidant [24,25], anti-inflammatory [26], neuroprotective [27], and anti-cancer activity [28] in different animal models. Thus, its oral administration could have promising health benefits; however, its applications are limited since morin is a BCS class IV molecule of difficult pharmaceutical formulations [29,30], which has very low oral bioavailability; studies suggest that in order to improve it, the intestinal first-pass effect should be avoided [31]. Nonetheless, selecting $\mathrm{MH}$ as a molecule probe to study its release behavior from a nanoantioxidant carrier and evaluating the impact that the surface polyphenolic layer of this nanosystem has on the release mechanism remains a challenge in pharmaceutical interest, which seeks to optimize potential formulations that include these novel nanoantioxidants. As far as we know, there are no reports on drug release from silica-based antioxidant systems. Therefore, the goal of this work was to synthesize surface-functionalized mesoporous silica nanoparticles with an antioxidant molecule to study the incorporation of morin and its subsequent release. To achieve the above, rosmarinic acid (RA), an ester of caffeic acid and 3,4-dihydroxyphenyllactic acid [32,33] with several promising biological activities, such as anti-inflammatory [34], anti-diabetic [35], prevention of Alzheimer's disease [36], and potent antioxidant activity [32,33], was chosen to immobilize it onto mesoporous silica nanoparticles. Thus, RA could maintain its remarkable antioxidant activity due to both caffeoyl and 2-oxyphenylpropanoyl moieties, which allows the generation of a hybrid antioxidant nanocarrier. All the materials were properly characterized and the antioxidant activity of the system evaluated. To elucidate the release mechanism, different kinetic models were used.

\section{Materials and Methods}

\subsection{Materials}

Morin hydrate $(\mathrm{MH}, \geq 85 \%)$, rosmarinic acid (RA, $\geq 98 \%$ ), tetraethyl orthosilicate (TEOS, 98\%), (3-aminopropyl)triethoxysilane (APTES, $\geq 98 \%$ ), hexadecyltrimethylammonium chloride solution (CTAC, 25 wt.\%), N-(3-dimethylaminopropyl)-N'-ethylcarbodiimide hydrochloride (EDC, $\geq 98 \%$ ),

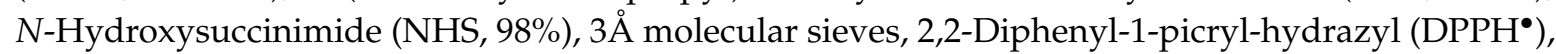
trifluoroacetic acid (TFA, $\geq 99 \%$ ), and pancreatin from porcine pancreas (USP specifications) were 
purchased from Sigma-Aldrich (St. Louis, MO, USA). A dialysis bag (SnakeSkin ${ }^{\circledR}$ Dialysis Tubing, molecular weight cutoff (MWCO) of 10,000 Da) was purchased from Thermo Scientific (Rockford, IL, USA). Ethanol (HPLC grade), sodium hydroxide $(\mathrm{NaOH}, \geq 98 \%)$, acetic acid $(\mathrm{AcOH}$, acs reagent for analysis), hydrochloric acid fuming ( $\mathrm{HCl}$, acs reagent $37 \%$ ), acetonitrile (HPLC grade), methanol (HPLC grade), and pepsin from porcine gastric mucosa (0.7 FIP-U/mg) were obtained from Merck (Darmstadt, Germany). Deionized water (Milli-Q, $18.2 \mathrm{M} \Omega \cdot \mathrm{cm}$ ) was used in all experiments in this study. All materials were used as received.

\subsection{Preparation of Mesoporous Silica Nanoparticles (MSN)}

MSN were synthesized using a previously reported method with slight modification $[37,38]$. Briefly, for typical synthesis, $6 \mathrm{mmol}$ of TEOS was added to a solution containing CTAC (1.5 mmol), deionized water $(150 \mathrm{~mL})$, and $\mathrm{NaOH}(1.1 \mathrm{~mL}, 2 \mathrm{M})$ at $80^{\circ} \mathrm{C}$; the mixture was then stirred for $2 \mathrm{~h}$. Silica nanoparticles were obtained by centrifugation at 11,000 rpm for $15 \mathrm{~min}$ and washed with ethanol and water. The surfactant was removed using an acid ethanolic solution $(1.2 \mathrm{M} \mathrm{HCl}$ final concentration) at $80^{\circ} \mathrm{C}$ for $18 \mathrm{~h}$. This procedure was performed twice. Finally, the product was thoroughly washed with ethanol and water.

\subsection{Preparation of Amino-Functionalized Mesoporous Silica Nanoparticles (AMSN)}

MSN were surface amino-functionalized using previously reported procedures [21]. Briefly, 300 mg of MSN were suspended in ethanol and $500 \mu \mathrm{L}$ of APTES were added; then the mixture was stirred at $40{ }^{\circ} \mathrm{C}$ for $12 \mathrm{~h}$. The AMSN were obtained by centrifugation at $11,000 \mathrm{rpm}$ for $15 \mathrm{~min}$ and washed with ethanol.

\subsection{Immobilized of Rosmarinic Acid onto Amino-Functionalized Mesoporous Silica Nanoparticles (Nano-RA)}

RA was conjugated onto silica nanoparticles by coupling its $-\mathrm{COOH}$ group to the $-\mathrm{NH}_{2}$ groups of AMSN using the EDC/NHS coupling agents, according to previously reported procedure [21]. To activate the RA, $0.14 \mathrm{mmol}$ of RA, $1.1 \mathrm{mmol}$ of EDC and $0.56 \mathrm{mmol}$ of NHS were suspended in water and homogenized for 20 min under $\mathrm{N}_{2}$ atmosphere. Then, the mixture was added dropwise to a suspension of AMSN, and the reaction was allowed to proceed with gentle stirring at room temperature under an $\mathrm{N}_{2}$ atmosphere for $6 \mathrm{~h}$. The resulting product was collected by centrifugation and thoroughly washed with ethanol and water to remove all by-products and/or unreacted reagents. The RA conjugation was quantified using an indirect HPLC method.

\subsection{Morin Hydrate-Loading Procedure}

For MH loading in the antioxidant nanosystem, an impregnation/solvent evaporation technique was used [39]. To this end, $25 \mathrm{mg}$ of nano-RA ( $5 \mathrm{mg} / \mathrm{mL}$ suspension) were mixed with $25 \mathrm{mg}$ of $\mathrm{MH}$ in a round bottom flask using methanol as solvent, and the suspension was stirred for $12 \mathrm{~h}$. Then, the solvent was slowly evaporated at $25^{\circ} \mathrm{C}$ using a rotary evaporator to $1 \mathrm{~mL}$ to produce a gradually increase concentration gradient of $\mathrm{MH}$ between the external solution and the nanoparticles, in order to favor the uptake of MH into mesopores. Subsequently, the MH loaded nano-RA samples were collected by centrifugation and the supernatant quantified by HPLC to determine the drug loading percentage (\% DL), according to the following Equation (1):

$$
\% D L=\frac{M H_{\text {initial }}-M H_{\text {free }}}{\text { Total weight }} \times 100
$$

where, $M H_{\text {initial }}$ and $M H_{\text {free }}$ are the amounts of morin initially added to the preparation of $\mathrm{MH}$-loaded nano-RA and the amount of non-impregnated morin determined by the HPLC method, respectively. Total weight corresponds to the total amount of the antioxidant nanosystem and morin in the final preparation. 


\subsection{Characterization}

The zeta potential and hydrodynamic diameter of the nanoparticles were obtained using a Malvern Zetasizer Nano ZS90 (Malvern, UK) with a detection angle of $173^{\circ}$ and equilibration time of $120 \mathrm{~s}$. Each measurement was performed three times. For the determination of zeta potentials, the nanoparticles were suspended in deionized water. Transmission electron microscopy (TEM) images were taken on a Hitachi HT7700 model microscope, with an accelerating voltage of $120.00 \mathrm{kV}$. N 2 adsorption-desorption isotherms were measured on a Quantasorb system Model QS-17 (Quantachrome Instrument, Boynton Beach, FL, USA) and specific surface area was obtained using the multipoint BET method. Desorbed volume was obtained in the relative pressure range of 0.05-0.95. All samples were outgassed for $2 \mathrm{~h}$ at $110{ }^{\circ} \mathrm{C}$ under $\mathrm{N}_{2}$ flow. Fourier-transform infrared (FT-IR) spectra were recorded on a Nicolet iS5 instrument (Thermo Scientific, USA) with $4-\mathrm{cm}^{-1}$ resolution, between 4000 and $500 \mathrm{~cm}^{-1}$, and the final spectrum corresponds to an average of 16 scans. The physical state of the pure MH, pure RA, MH-loaded nano-RA, and physical mixture of MH, RA, and nano-RA samples were conducted by differential scanning calorimetry (DSC). DSC curves were obtained on SETARAM 131 Evo apparatus (Setaram instrumentation K\&P technologies, France). All samples were accurately weighted (1-4 mg), sealed in aluminum pans, and heated from 30 to $320{ }^{\circ} \mathrm{C}$ at a heating rate of $10{ }^{\circ} \mathrm{C} \cdot \mathrm{min}^{-1}$.

Determination of RA grafting onto nanoparticles was also quantified using an HPLC indirect method previously reported with slight modifications [40]. Chromatographic analysis was performed on an HPLC LC-20AT (Shimadzu, Tokyo, Japan), equipped with a model LC-20ATX2units pump, a Sil-20A autosampler, a CTO-20A column oven, an SPD-M20A diode array detector, and an InertSustain C18 column $(4.6 \times 250 \mathrm{~mm}, 5-\mu \mathrm{m}$ particle size). Gradient elution was performed using a mobile phase consisting of a mixture of phase A ( $0.6 \%$ acetic acid solution) and phase $\mathrm{B}$ (acetonitrile). The starting mobile phase consisted of $80 \% \mathrm{~A}$ and $20 \% \mathrm{~B}$ for $4 \mathrm{~min}$; then, from 5 to $15 \mathrm{~min}$, the mobile phase was $40 \% \mathrm{~A}$ and $60 \% \mathrm{~B}$, and finally from 16 to $17 \mathrm{~min}$, the mobile phase was $80 \% \mathrm{~A}$ and $20 \%$ $\mathrm{B}$; the flow rate was $1.0 \mathrm{~mL} / \mathrm{min}$. The sample injection volume was $20 \mu \mathrm{L}$, run time was $17 \mathrm{~min}$, and retention time was $12.9 \mathrm{~min}$. A PDA detector was set at $332 \mathrm{~nm}$. Determination of MH-loaded nano-RA was also quantified using the same HPLC LC-20AT (Shimadzu, Japan) instrument described above, equipped with a Kromasil C8 column $(150 \times 4.6 \mathrm{~mm})$. For $\mathrm{MH}$ analysis, mobile phase consisting of TFA $0.1 \%$ :acetonitrile $(70: 30, v / v)$ was pumped at a flow rate of $1 \mathrm{~mL} / \mathrm{min}$ and sample injection volume was $20 \mu \mathrm{L}$. The run time was $16 \mathrm{~min}$, retention time was $5.45 \mathrm{~min}$, and the PDA detector was set at 355 $\mathrm{nm}$. Results for all the samples were obtained by triplicate analysis.

\subsection{Antioxidant Activity Evaluation (DPPH $H^{\bullet}$}

$\mathrm{DPPH}^{\bullet}$ free radical scavenging activity of nano-RA was evaluated according to previously reported methods [41]. Briefly, aliquots of RA, either free or nanoparticle-bound, with varying final concentrations $(0.43,1.1,2.2,4.3,6.5$ and $10.8 \mu \mathrm{g} / \mathrm{mL})$ were added to a 5 -mL volumetric flask and mixed with $1 \mathrm{~mL}$ of a DPPH${ }^{\bullet}$ solution freshly prepared in methanol (50 $\mu \mathrm{M}$ final concentration). Mixtures were stirred in the dark at room temperature for $20 \mathrm{~min}$, then centrifuged, and the supernatant was measured spectrophotometrically at $515 \mathrm{~nm}$ using an Agilent UV/vis spectrophotometer (Agilent 8453 model, Santa Clara, CA, USA). The radical-scavenging activity (\%RSA) was calculated according to the following Equation (2):

$$
\% R S A=\left(\frac{A_{0}-A_{1}}{A_{0}}\right) \times 100
$$

where $A_{0}$ is the control absorbance (DPPH${ }^{\bullet}$ solution only) and $A_{1}$ is the absorbance of the sample after treatment.

\subsection{In Vitro Morin Hydrate Release Analysis}

The in vitro release studies were carried out by dialysis technique, adapting previously reported procedures [42], using simulated gastric fluid (SGF) ( $\mathrm{pH} 1.2 \pm 0.1$ ) and simulated intestinal fluid (SIF) 
( $\mathrm{pH} 6.8 \pm 0.1)$ containing pepsin and pancreatin, respectively, as biorelevant media [43]. In each experiment, the dialysis bag was soaked and then filled with $4 \mathrm{~mL}$ of each sample containing an equivalent amount of $1 \mathrm{mg}$ of $\mathrm{MH}$. Subsequently, the dialysis bag was immersed in a tube containing 40 $\mathrm{mL}$ of biorelevant medium and kept at $37^{\circ} \mathrm{C}$ under stirring at $100 \mathrm{rpm}$. Sink conditions were ensured throughout the experiments. At predetermined time intervals, aliquots of $1 \mathrm{~mL}$ were withdrawn from the release medium and immediately replaced with $1 \mathrm{~mL}$ of fresh medium. Each aliquot was filtered with a $0.22 \mu \mathrm{m}$ syringe filter and MH content was determined by HPLC. All the measurements were performed in triplicate and the data expressed as cumulative percentage of $\mathrm{MH}$ released versus elapsed time (h).

The $\mathrm{MH}$ release data from the nanoparticles were fitted using different kinetic models, including zero-order (Equation (3)), first-order (Equation (4)), Higuchi (Equation (5)), and Korsmeyer-Peppas (Equation (6)) models [44]:

$$
\begin{gathered}
Q_{t}=Q_{0}+K_{0} t \\
\ln Q_{t}=\ln Q_{0}+K_{1} t \\
Q_{t}=K_{H} \sqrt{t} \\
\frac{Q_{t}}{Q_{\infty}}=K_{K P} t^{n}
\end{gathered}
$$

where $Q_{0}$ and $Q_{t}$ is the initial amount of $\mathrm{MH}$ in the solution and the amount of $\mathrm{MH}$ dissolved at $t$ time, respectively. $Q_{\mathrm{t}} / Q_{\infty}$ is the fractional release of drug $(\mathrm{MH}) . K_{0}$ is the zero-order constant, $K_{1}$ is the first-order constant, $K_{\mathrm{H}}$ is the Higuchi constant, $K_{\mathrm{KP}}$ is the Korsmeyer-Peppas constant, and $n$ is the diffusional or release exponent.

\subsection{Statistical Analysis}

Data are presented as mean $\pm \mathrm{SD}$ of $n$ independent experiments. Data sets were analyzed by $R^{2}$ parameter and Student's $t$-test, followed by a Holm-Sidak post-hoc test, where applicable. A $p$-value $<0.05$ was considered significant. The DDSolver®add-In (Microsoft Excel) program and GraphPad Prism software version 6.01 (San Diego, CA, USA) were used for statistical analysis.

\section{Results}

In this work, an antioxidant material consisting of a mesoporous silica nanostructure and rosmarinic acid (nano-RA) was developed and characterized, to unravel the release mechanism of bioactive compounds from this drug delivery model system. Recently, we reported the preparation of an antioxidant-nanosystem based on caffeic acid attached to silica nanoparticles, which showed the ability to protect oxidant-sensitive molecules [21]. Employing similar protocols to those previously reported, the RA, an ester derived from a hydroxycinnamic acid, was successfully attached onto amino-functionalized mesoporous silica nanoparticles through an amide bond between the carboxylic acid of RA and APTES amino group on the surface of the nanoparticles (Figure 1a).

According to previous reports regarding the reaction time to graft a polyphenol by EDC/NHS coupling in polymeric matrices, $6 \mathrm{~h}$ of reaction time is sufficient to successfully attach RA on the surface $[16,21,45,46]$. In concordance, the grafted amount was $216.2 \mathrm{mg}$ of RA per gram of nanoparticle, yielding an $88 \%$ (Table 1). After the grafting process and using bare nanoparticles (MSN) as control, $\mathrm{MH}$ was loaded into nanoparticles using the impregnation/solvent evaporation technique (Figure 1b). The MH-loaded was $9.4 \% w / w$ and $23.1 \% w / w$ for MSN/MH and nano-RA/MH, respectively (Table 1); these values are expected due to MH being incorporated into the MSN pores and a small amount adsorbed on the surface. In the nano-RA, MH was also incorporated into the pore and, in addition, interacted with moieties of RA, producing a greater amount of MH adsorbed compared to bare MSN. The hydrodynamic diameter of all nanomaterials was measured (Figure 2c). In general, the size does not vary significantly with the different functionalization steps, maintaining an average of $205 \mathrm{~nm}$ with 
a good polydispersity index lower than 0.3 (Figure 2c, right $y$ axis), except in the case of nano-RA/MH, where the average hydrodynamic diameter increases up to $250 \mathrm{~nm}$ with a PdI value of 0.52 , probably due to the possible adsorption of morin in multilayers. This behavior has been previously reported by our group and is related to the coating properties of morin [47,48]. Nevertheless, any change in size was negligible and the zeta potential values (Figure $2 \mathrm{~d}$ ) suggest a suitable colloidal stability. In addition, the zeta potential values reveal change in surface charge from bare mesoporous silica nanoparticles $(-27 \mathrm{mV})$ to particles functionalized with amino groups $(+17 \mathrm{mV})$, then to particles with RA immobilized on surface through an amide bond $(-30 \mathrm{mV})$, and finally, to silica nanospheres with $\mathrm{MH}$ incorporated both in the pores and onto the surface $(-32 \mathrm{mV})$.

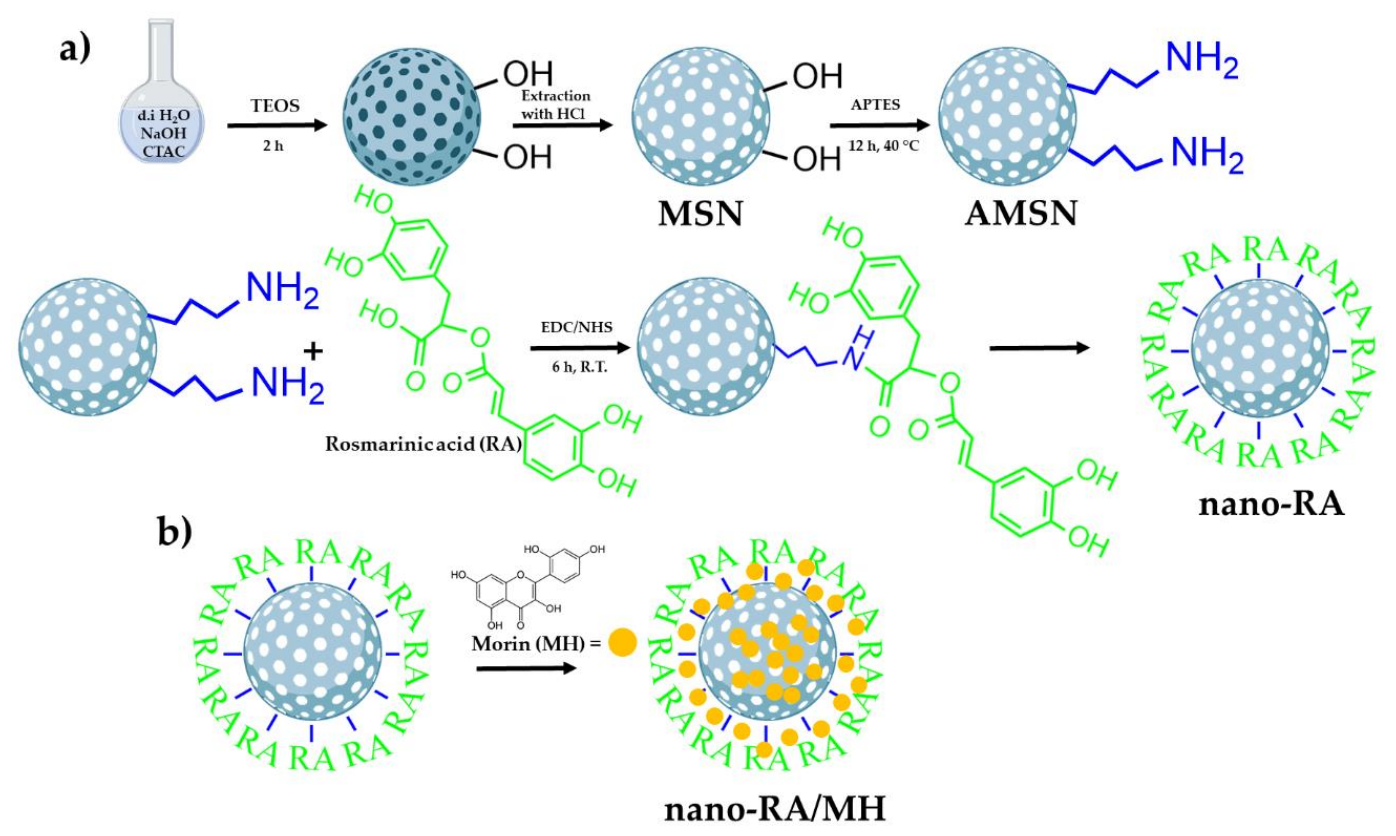

Figure 1. Schematic representation of the preparation of morin-loaded nanoantioxidants (nano-RA/MH). (a) Schematic path to obtain the antioxidant nanocarrier (nano-RA) and (b) schematic representation of the loading of morin in the nano-RA (nano-RA/MH).

Table 1. Summary of physical data of the tested nanomaterials.

\begin{tabular}{ccccc}
\hline Nanosystem & $S_{\text {BET }}\left(\mathbf{m}^{2} / \mathbf{g}\right)^{\mathbf{a}}$ & $\begin{array}{c}\text { Grafting } \\
(\mathbf{m g ~ R A} / \mathbf{g ~ N P})\end{array}$ & $\begin{array}{c}\text { \%MH Loading }^{\mathbf{b}} \\
(\boldsymbol{w} / \boldsymbol{w})^{\mathbf{b}}\end{array}$ & $\begin{array}{c}\text { Theoretical \%MH Loading } \\
(\boldsymbol{w} / \boldsymbol{w})\end{array}$ \\
\hline MSN & $840 \pm 10$ & - & - & - \\
nano-RA & $267 \pm 1.0$ & $216.2 \pm 3.8$ & - & - \\
MSN/MH & - & - & $9.4 \pm 0.8$ & 50 \\
nano-RA/MH & - & - & $23.1 \pm 3.5$ & 50 \\
\hline
\end{tabular}

${ }^{a}$ Determined using the multipoint BET method. ${ }^{b}$ Determined by HPLC methodology. BET method-BrunauerEmmett-Teller method; SBET-BET surface area; HPLC-High-performance liquid chromatography; MSN-Mesoporous silica nanoparticles; MSN/MH-morin-loaded mesoporous silica nanoparticles; nano-RA-rosmarinic acid-functionalized silica nanocarrier; nano-RA/MH - morin-loaded rosmarinic acid-functionalized silica nanocarrier. 
a)

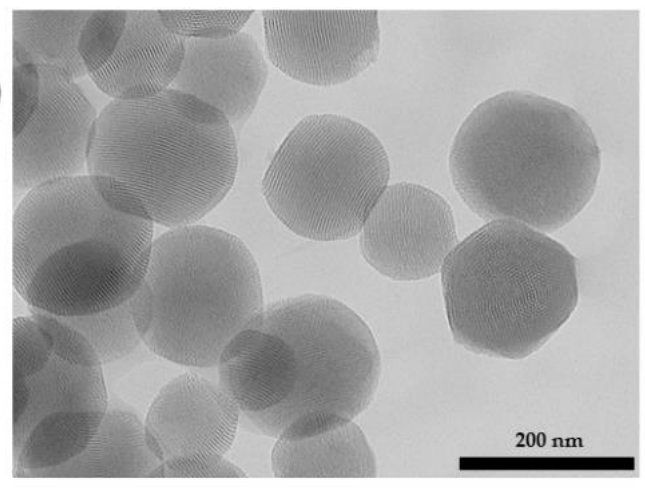

b)

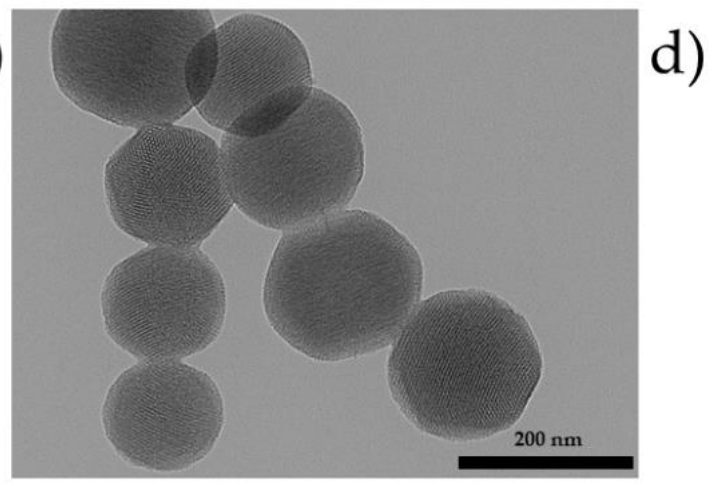

c)
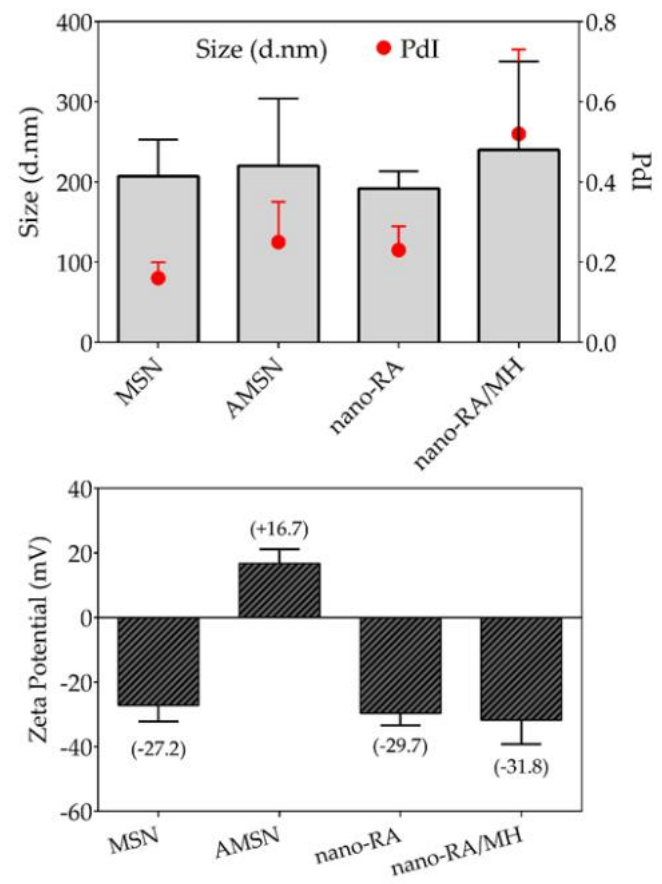

Figure 2. Transmission electron microscopy (TEM) micrographs and particle size distribution. (a) TEM image of bare mesoporous silica nanoparticles (MSN), (b) TEM image of rosmarinic acid-functionalized silica nanocarrier (nano-RA), (c) hydrodynamic diameter and polydispersity index (PdI) of nanomaterials by dynamic light scattering (DLS) measurement, and (d) zeta potential of nanomaterials.

The homogeneity of nanosystems was corroborated through the morphological features of nanomaterials obtained by TEM images (Figure 2a,b), where the particles were monodisperse porous spheres with a size of ca. $150.9 \pm 18.6 \mathrm{~nm}$; the surface functionalization does not affect the morphological features of studied nanosystems. In addition, the TEM images revealed that the nanoparticles are characterized by regular and well-ordered parallel pore channels, with a pore diameter $\sim 3.1 \mathrm{~nm}$, in agreement with those reported by other authors [37]. For bare MSN and nano-RA, the BET surface area determined were $840 \mathrm{~m}^{2} \cdot \mathrm{g}^{-1}$ and $267 \mathrm{~m}^{2} \cdot \mathrm{g}^{-1}$ (Table 1); this change, as expected, suggests that the RA molecules are linked in both the pore and outer surface of the nanoparticles. It is expected that this disposition of the RA molecules can affect the amount of MH loaded and its subsequent release, due to a greater interaction between $\mathrm{RA} / \mathrm{MH}$ than $\mathrm{MH} / \mathrm{MSN}$. In fact, these results are consistent with the high drug loading of $\mathrm{MH}(23 \% w / w)$ in nano-RA compared to bare MSN $(9 \% w / w)$.

In order to evaluate the surface functionalization of nanoparticles, the FTIR spectra of all nanosystems and the standard polyphenols were recorded (Figure 3). MSN spectrum (black line) exhibit a broad band at $3385 \mathrm{~cm}^{-1}$ corresponding to adsorbed water and hydroxyl stretching of the silanol group, consistent with the presence of two characteristic peaks at $1638 \mathrm{~cm}^{-1}(\mathrm{H}-\mathrm{OH}$ twisting band) and $960 \mathrm{~cm}^{-1}$ attributed to Si-O band stretch of surfaces $\mathrm{Si}-\mathrm{OH}$ groups. Furthermore, a broad characteristic band at $1060 \mathrm{~cm}^{-1}$ corresponding to stretching vibration of siloxane groups is also present. 


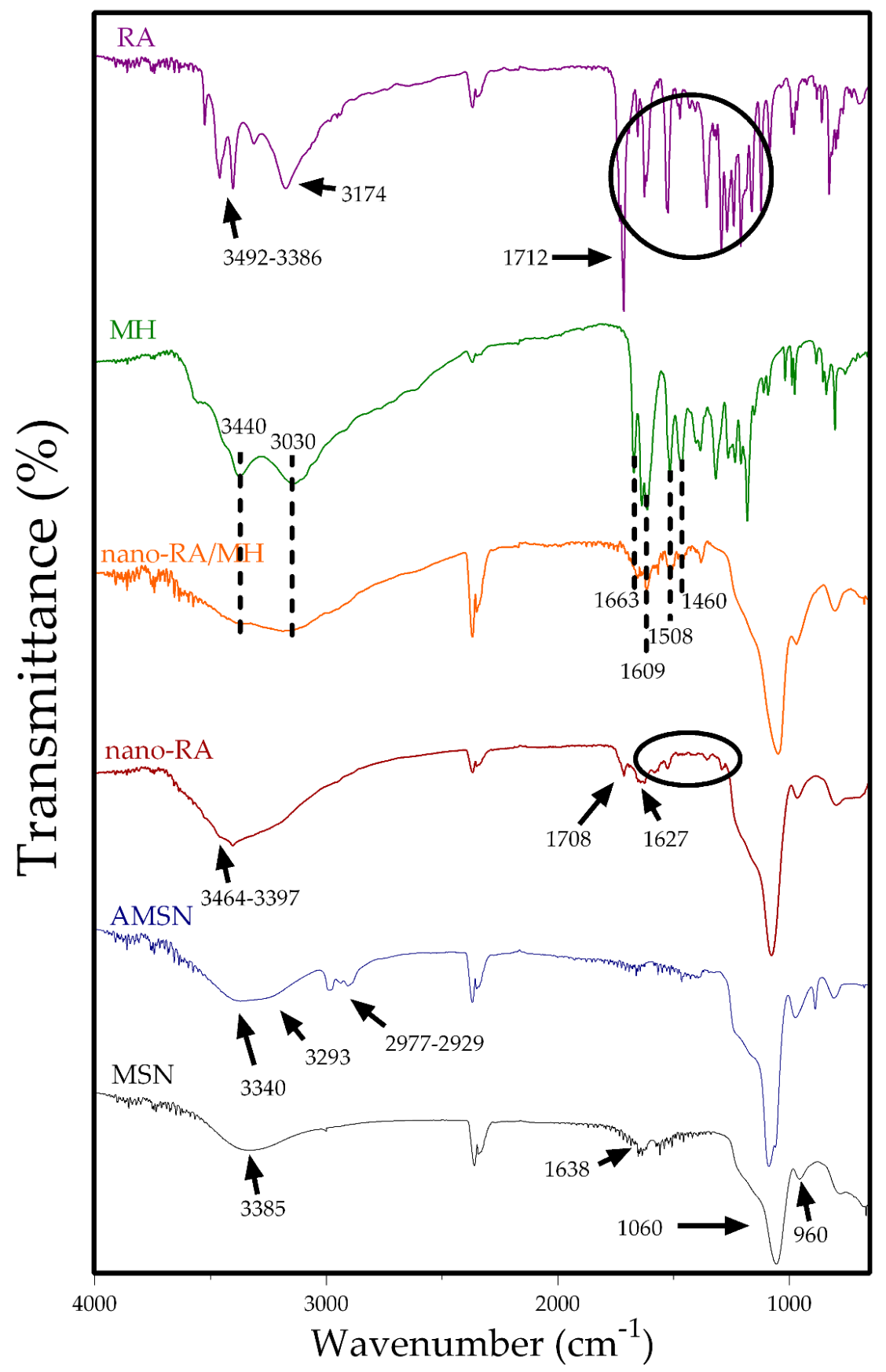

Figure 3. Fourier-transform infrared (FT-IR) spectra of MSN (black line), AMNS (blue line), nano-RA (red line), nano-RA/MH (orange line), $\mathrm{MH}$ (green line), and RA (purple line).

After amino-functionalization, AMSN (blue line) showed four important peaks at 3340, 3293, 2977, and $2929 \mathrm{~cm}^{-1}$, where the former two are related to $\mathrm{NH}_{2}$ stretching vibration and the last two peaks are attributed to the $\mathrm{C}-\mathrm{H}$ stretch of aminopropyl chain of APTES [49]. The RA spectrum (purple line) indicates the main peaks at 3492 and $3386 \mathrm{~cm}^{-1}$ attributed to stretching of free -OH groups of RA, and the peaks at 3174 and $1712 \mathrm{~cm}^{-1}$ are due to $-\mathrm{OH}$ stretching and $-\mathrm{C}=\mathrm{O}$ stretching vibration of carboxylic acid, respectively. Also, the spectrum showed the characteristic fingerprints of RA, where the principal peaks at $1648 \mathrm{~cm}^{-1}$ and 1517 and $1471 \mathrm{~cm}^{-1}$ were assigned to $-\mathrm{C}=\mathrm{O}$ stretching of conjugated carbonyl group and stretching related to the aromatic ring, respectively. The nano-RA spectrum (red line) also exhibits several of the characteristics peaks in the fingerprint zone $\left(1521\right.$ and $\left.1458 \mathrm{~cm}^{-1}\right)$ and the presence of a broad band $\left(3510-3100 \mathrm{~cm}^{-1}\right)$ due to $-\mathrm{OH}$ stretching and two weak peaks at 3464 and 
$3397 \mathrm{~cm}^{-1}$ due to free -OH of RA. Additionally, two differences are crucial when comparing nano-RA spectrum to the AMSN and RA spectra. First, the absence of the peak corresponding to vibration of the $-\mathrm{OH}$ of carboxylic acid, and secondly, the presence of two new bands at 1708 and $1627 \mathrm{~cm}^{-1}$ attributed to $(-\mathrm{C}=\mathrm{O})$ amide I and $(-\mathrm{C}-\mathrm{N})$ amide II, due to the formation of amide bond between $\mathrm{NH}_{2}$ of APTES and carboxylic acid of RA, confirming the successful grafting of RA onto the surface of mesoporous silica nanoparticles [16]. On the other hand, in the MH spectrum (green line) were highlighted bands at $3440-3030 \mathrm{~cm}^{-1}$ of the $-\mathrm{OH}$ group of morin, at $1663 \mathrm{~cm}^{-1}$ of $-\mathrm{C}=\mathrm{O}$ of the carbonyl group in the $\mathrm{C}$ ring of morin, and the peaks at 1609,1508 and $1460 \mathrm{~cm}^{-1}$ attributed to $\mathrm{C}=\mathrm{C}$ stretching vibration in the aromatic ring. The same previous peaks are present in the nano-RA/MH spectrum (orange line), suggesting the presence of morin in the surface of nanomaterial (considering the external zone of pores).

Differential scanning calorimetry (DSC) analysis was using to investigate the physical state of $\mathrm{MH}$ after being incorporated in nanosystems (Figure 4), and the DSC thermograms were designated as pure MH (green line), pure RA (purple line), MSN (black line), AMSN (blue line), nano-RA (red line), and nano-RA/MH (orange line).

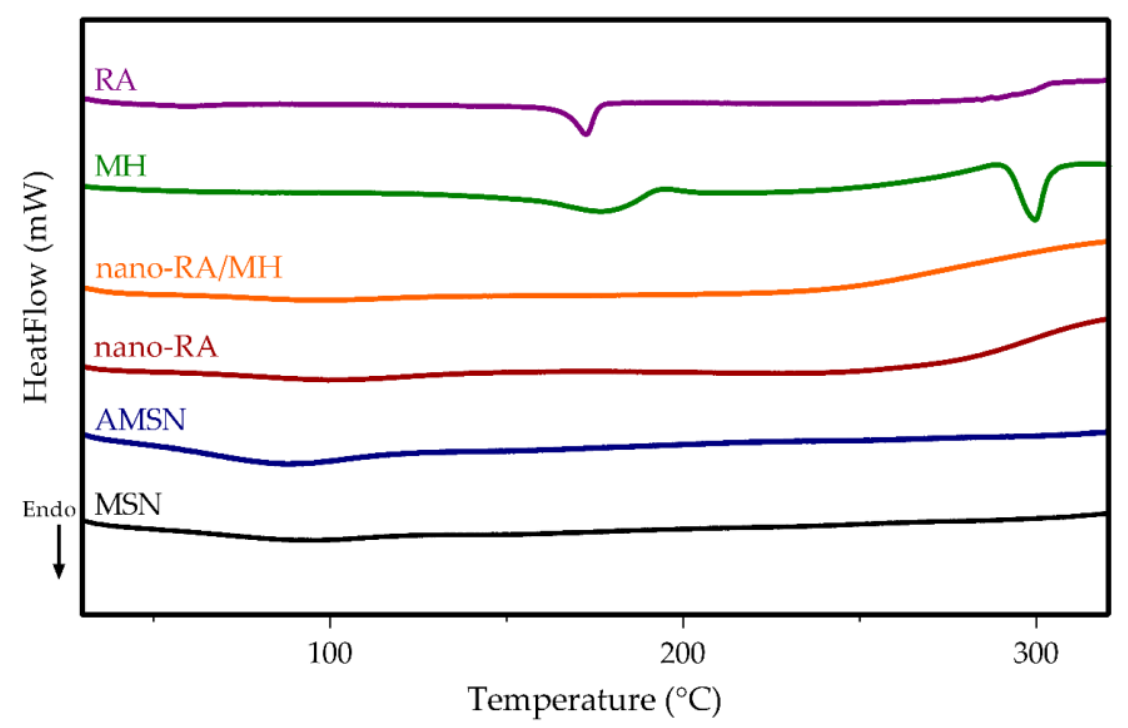

Figure 4. DSC thermogram of MSN (black line), AMSN (blue line), nano-RA (red line), nano-RA/MH (orange line), MH (green line), and RA (purple line).

The curve corresponding to pure $\mathrm{MH}$ displays a sharp endothermic peak at $296{ }^{\circ} \mathrm{C}$, which corresponds to the intrinsic melting point [50]. However, this peak did not appear in the nano-RA/MH sample, indicating that the MH was in a noncrystalline state when incorporated into the nanosystem, both in the pore and onto the surface interacting with the grafted RA; this molecular interaction favors the solubility of MH. Additionally, pure RA displays a sharp endothermic peak at $171{ }^{\circ} \mathrm{C}$ [51], but this peak, as expected, cannot be observed in the curve corresponding to nano-RA or the nano-RA/MH, due to the covalent interaction between RA and the surface of the mesoporous silica nanoparticles.

The $\mathrm{DPPH}^{\bullet}$ assay is an easy-to-use, low cost, and fast method to screen antioxidant activity (number of reduced $\mathrm{DPPH}^{\bullet}$ per antioxidant mole); it has been widely used by several authors to evaluate this activity of polyphenols incorporated in silica or polymeric matrices [16,52-54]. In the present work, we evaluated the antiradical activity expressed as radical scavenging activity percentage (\%RSA) versus RA concentration of free RA and nano-RA, in the concentration range of 0.43-10.8 $\mu \mathrm{g} / \mathrm{mL}$ (Figure 5). As the concentration of free RA increases, the \%RSA increases, reaching a 50\% of $\mathrm{DPPH}^{\bullet}$ deactivation approximately at a concentration of $2.5-3 \mu \mathrm{g} / \mathrm{mL}$, which is consistent with literature reports [55-57]. 


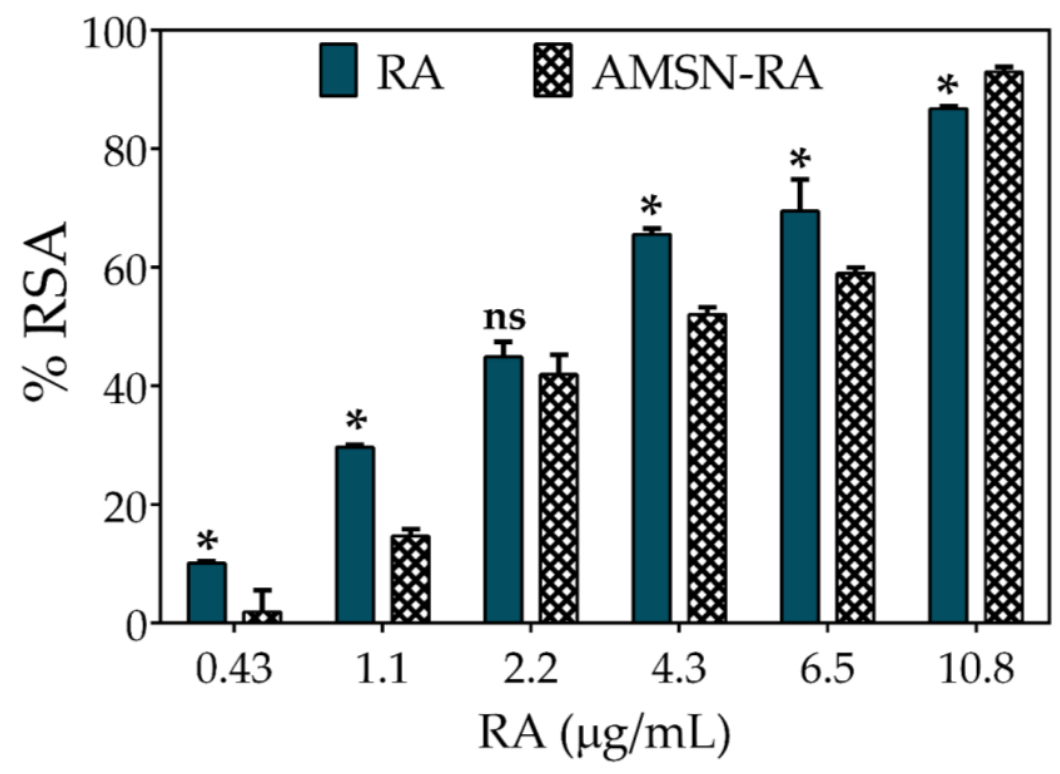

Figure 5. Antioxidant activity comparison between RA (rosmarinic acid standard) and nano-RA against $\mathrm{DPPH}^{\bullet}$ expressed as percentage of radical scavenging activity (\%RSA) versus RA concentration. Results are reported as means $\pm \mathrm{SD}(n=3) .{ }^{*} p<0.05 ;$ ns, not significant.

Xie and Schaich studied the kinetics patterns of different phenol reactions with DPPH ${ }^{\bullet}$, and classified them into five groups. According to the reactivity, they were denominated as instantaneous (group 1), very fast (group 2), moderate (group 3), slow (group 4), and no reaction (group 5). Considering this work, RA reduces DPPH ${ }^{\bullet}$ through a moderate kinetic pattern, where it first acts by a single electron transfer (SET) mechanism and as the reaction progresses, the hydrogen atom transfers (HAT) and steric hindrance or mixed mechanisms appear $[58,59]$. On the other hand, nano-RA also shows a similar concentration-dependence activity but with a slight decrease in the $\%$ RSA, exhibiting a $50 \%$ of $\mathrm{DPPH}^{\bullet}$ deactivation at RA nominal concentration of $\sim 4.3 \mu \mathrm{g} \mathrm{mL}^{-1}$. This behavior could be explained by the immobilization of RA on the surface of nanoparticles and the tendency of $\mathrm{DPPH}^{\bullet}$ to adsorb onto nanoparticles; when combined, they are a limitation to the free diffusion of involved molecules, hindering antioxidant activity. This hampering effect of nanoparticles has a pivotal role, since the radical site of $\mathrm{DPPH}^{\bullet}$ is protected inside a reaction cage formed by nitro groups oriented above and below it, by an ortho $\mathrm{H}$ atom on each of the phenyl rings, and by twisting of the ring [59]; therefore, considering this orientation, the steric accessibility is crucial for $\mathrm{DPPH}^{\bullet}$ deactivation. Thus, in systems where nanoparticles limit accessibility, an attenuation in the activity can be expected. However, although the antioxidant activity of RA decreases slightly, the nanomaterial shows a high antioxidant activity; this behavior has been reported by other authors $[16,21,52]$. These results confirm that the RA scaffold is able to scavenge a free radical when favorably oriented on the surface of nanoparticles.

As mentioned earlier, $\mathrm{MH}$ is a flavonoid with several reported pharmacological activities; however, its poor aqueous solubility produce low oral bioavailability [29], limiting its pharmaceutical applications. As many other drugs, polyphenol absorption occurs mainly in the small intestine [60]; however, in the case of $\mathrm{MH}$, the information about its oral delivery is limited. Nevertheless, pharmacokinetic studies in animal models by different authors have reported that $\mathrm{MH}$ absorption occurs mainly in the small intestine and the colon $[30,31,61]$. Some of these studies suggest that to improve the oral bioavailability of $\mathrm{MH}$, a BCS class IV drug, it is crucial to avoid both efflux and intestinal metabolism. Thus, the release of more or less $\mathrm{MH}$ in the absorption site would not be a preponderant factor, since the process still depends on the physicochemical properties of the molecule in the biological milieu. However, it is important to consider that although the release mechanism of some large and small molecules from silica matrices has been widely reported [62], to our knowledge, there are no reports on the release mechanism of polyphenols from systems called nanoantioxidants $[13,63]$ based on 
silica. Unveiling this mechanism could anticipate biological behavior and optimize the design of pharmaceutical formulations to improve oral bioavailability. In addition, the polyphenolic surface of these novel nanosystems, also classified as bioinspired carriers, has been reported as a component that could enhance the biocompatibility, biodegradability, and targeting properties of the silica materials [64]. Thus, the implications of the polyphenol-functionalized nanoparticle on the drug release need to be evaluated. Therefore, the in vitro release profile of MH-loaded antioxidant-nanosystem (nanoantioxidant) in two biorelevant media were studied (Figure 6).

a)

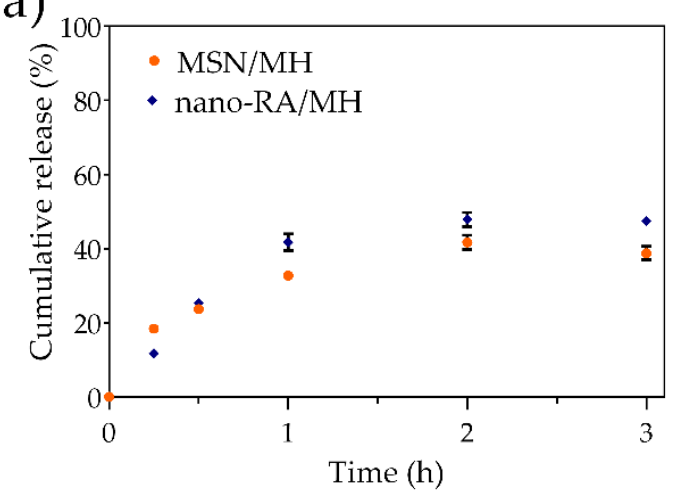

b)

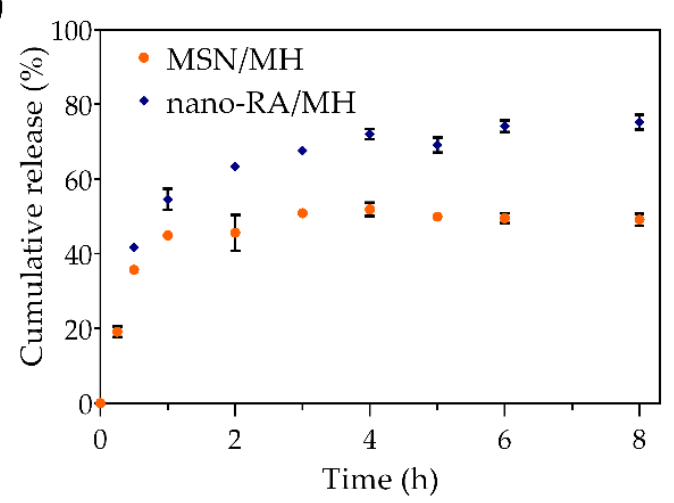

Figure 6. In vitro release profile of morin loaded in MSN (MSN/MH) and nano-RA (nano-RA/MH), in (a) simulated gastric fluid and (b) simulated intestinal fluid, at $37^{\circ} \mathrm{C}$.

In the first stage (Figure 6a), the nanosystem was evaluated in simulated gastric fluid (SGF, pH 1.2) where the release of $\mathrm{MH}$ was $<40 \%$ both in bare nanoparticles and antioxidant-nanosystem, reaching a plateau at $2 \mathrm{~h}$. In the second stage (Figure $6 \mathrm{~b}$ ), the nanosystem was evaluated in simulated intestinal fluid (SIF, $\mathrm{pH}$ 6.8), where the release of $\mathrm{MH}$ from bare nanoparticles reached the maximum cumulative release at $2 \mathrm{~h}(<50 \%)$. On the other hand, the release of $\mathrm{MH}$ from the antioxidant nanosystem was greater than that from bare nanoparticles, reaching a maximum $\mathrm{MH}$ release of $74 \%$ at $4 \mathrm{~h}$; the system then showed a sustained release until the end of the experiment. Other authors have reported the difficulty of administering high doses of morin orally, because it tends to form a saturated solution in the intestinal tract, hindering the drug dissolution process. In this context, the sustained release of a drug from the antioxidant nanosystem could be beneficial. When the nanoparticles are in SGF, no significant difference in the low sustained release of $\mathrm{MH}$ from MSN/MH and nano-RA/MH systems are observed, and the release of $\mathrm{MH}$ from the nano-RA/MH is slightly higher. This could be explained because at acidic $\mathrm{pH}$ of SGF, both the $\mathrm{MH}$ and RA species are protonated, which does not favor the solubility of $\mathrm{MH}$; therefore, only a small amount of $\mathrm{MH}$ diffuses from the pore to the medium, but a slightly higher amount of $\mathrm{MH}$ is released from the antioxidant-nanosystem, due to the adsorbed $\mathrm{MH}$ on the surface that interacts with RA. A different situation is observed when the nanoparticles are in SIF. In this medium, the RA and MH are partially ionized, which favors both the solubility of the $\mathrm{MH}$ and its repulsion with the polyphenolic surface, triggering a greater release; in particular, the antioxidant-nanosystem produces a higher release than the bare nanoparticles due to the MH being adsorbed on the surface, enhanced by the RA-MH interaction, and the MH-loaded in the pores.

According to the literature, the drug release process comprises of four pivotal stages: (i) entry of the release medium into the material matrix, in response to the osmotic pressure produced by the concentration gradient of the drug between the solution and the particle surface; (ii) drug dissolution in the release medium; (iii) drug diffusion through the particle matrix due to a concentration gradient; and (iv) drug diffusion and transport within the release medium [65,66]. Hence, to understand the specific MH release mechanism from the nanoparticles, the data were fitted according to four kinetic models commonly used and suitable to analyze the release of drug from silica nanoparticles. In order to discriminate which mathematical model best fits the kinetic data, the $\mathrm{R}^{2}$ parameter was used. The 
release data were best fit by Higuchi and Korsmeyer-Peppas models, independent of the biorelevant media tested (Table 2), demonstrating that MH release from nanosystems involves a diffusion process. A deeper insight into the release mechanism was performed using the release exponent value $(n)$ according to the Korsmeyer-Peppas model, which is classified in different categories [67]. For spherical materials, if $n<0.43$, the drug release mechanism follows a pseudo-Fickian diffusion (commonly for polydisperse systems); $n \sim 0.43$ indicates Fickian diffusion; when $0.43<n<0.85$, anomalous (non-Fickian) transport is involved; if $n \sim 0.85$ indicated non-Fickian Case-II transport; and finally, if $n$ $>0.85$ the predominant drug release mechanism is a Super Case II transport.

Table 2. Kinetics parameters of the release profile of nanosystems in simulated gastric fluid and simulated intestinal fluid.

\begin{tabular}{|c|c|c|c|c|c|c|c|c|c|}
\hline \multirow{3}{*}{$\begin{array}{c}\text { Medium } \\
\text { Release }\end{array}$} & \multirow{3}{*}{ Nanosystem } & \multicolumn{8}{|c|}{ Kinetic Model } \\
\hline & & \multicolumn{2}{|c|}{ Zero-order } & \multicolumn{2}{|c|}{ First-order } & \multicolumn{2}{|c|}{ Higuchi } & \multicolumn{2}{|c|}{ Korsmeyer-Peppas } \\
\hline & & $\begin{array}{c}K_{0} \\
\left(\mathrm{mg} \mathrm{h}^{-1}\right)\end{array}$ & $R^{2}$ & $\begin{array}{c}K_{1} \\
\left(h^{-1}\right)\end{array}$ & $R^{2}$ & $\begin{array}{c}K_{\mathrm{H}} \\
\left(\mathrm{mg} t^{-0.5}\right)\end{array}$ & $R^{2}$ & $n$ & $R^{2}$ \\
\hline \multirow{2}{*}{ SGF } & MSN/MH & 0.13 & 0.96 & 0.44 & 0.91 & 0.26 & 0.99 & 0.42 & 0.99 \\
\hline & nano-RA/MH & 0.19 & 0.83 & 0.69 & 0.73 & 0.39 & 0.92 & 0.68 & 0.91 \\
\hline \multirow{2}{*}{ SIF } & MSN/MH & 0.03 & 0.422 & 0.08 & 0.37 & 0.33 & 0.88 & 0.43 & 0.88 \\
\hline & nano-RA/MH & 0.05 & 0.56 & 0.11 & 0.45 & 0.36 & 0.86 & 0.54 & 0.88 \\
\hline
\end{tabular}

In particular, the $n$ values for $\mathrm{MH}$ release from bare nanoparticles in SGF and SIF were 0.42 and 0.43 , respectively, which indicates a Fickian diffusion mechanism. These results are in concordance with other reports for porous matrix structures $[62,66]$. Otherwise, it is interesting to note that when the antioxidant (RA) is on the nanoparticles surface, the $n$ values in SGF and SIF change to 0.68 and 0.54 , respectively, indicating an anomalous non-Fickian transport. This could be explained by considering the interaction between RA and $\mathrm{MH}$ on the surface and the layer-like arrangement on the nanoparticles. Tran and Lee reported similar results regarding the change in the diffusion mechanism from bare nanoparticles to surface functionalized layer-like arrangement nanoparticles [68].

It is well known that in the Fickian diffusion, the solvent diffuses into the matrix at a high rate and polymeric relaxation has a low rate, inducing the formation of a gradient of solvent penetration. On the other hand, in the anomalous transport, the rate of solvent diffusion and the polymeric relaxation possess similar magnitudes [69]. Therefore, this anomalous transport is characterized by a coupling of the diffusion and the matrix erosion mechanism, i.e., the release is controlled by more than one process. In this sense, several authors have reported the degradation of silica matrix in different biorelevant media and at different average times; for example, 3 days [70], 8-12 days [6], 8 h [71], and 24-96 h [72]. On the other hand, Braun et al. reported no degradation of silica matrix when exposed to SGF for $6 \mathrm{~h}$ [73]. In any case, the degradation process as a basis for explaining the change in the diffusion mechanism is not considered in our work, because of the short experimental times involved. Thus, to explain the behavior of $\mathrm{MH}$ release when the polyphenol RA is grafted in the nanoparticles, it is necessary to consider a possible layer-like arrangement on the surface. Mainly, the $-\mathrm{OH}$ and $-\mathrm{C}=\mathrm{O}$ groups belonging to $\mathrm{MH}$ and $\mathrm{RA}$ can interact through hydrogen-bonding and due to the coating capacity of $\mathrm{MH}$, form more than one surface layer that is not removed with washing after the synthesis $[47,74,75]$. As mentioned earlier, the release occurs in the SGF and SIF media, but when the $\mathrm{pH}$ increases, the $\mathrm{MH}$ and $\mathrm{RA}$ molecules are partially deprotonated and the electrostatic repulsive force between them facilitates the release, and the outer polyphenolic layers are removed, to a greater extent than at acidic $\mathrm{pH}$, due to the process of $\mathrm{MH}$ desorption. In addition, it is noteworthy that no significant burst release was observed in the release profile. Thereby, the release mechanism should take place by two processes: (i) the diffusion through the pores and (ii) the ionization of $\mathrm{MH}$ and subsequent slow desorption. The last process is crucial because it resembles the erosion mechanism mentioned above, hindering the transport and disrupting the normal Fickian diffusion from pores, 
explaining the change in the mechanism from Fickian diffusion to anomalous non-Fickian transport both in SGF and SIF media, for the nano-RA system.

Considering that anomalous transport involves both the Fickian diffusion and relaxation/erosion mechanisms, it is interesting to identify the main process in the $\mathrm{MH}$ release from the antioxidant-nanosystem. To achieve this, the empirical model proposed by Nikolaos Peppas and Jennifer Sahlin was used [67]. This model aims to calculate the approximate contributions of the diffusional and relaxation mechanisms in an anomalous solute release process, considering them additives according to the following equation:

$$
\frac{M_{t}}{M_{\infty}}=k_{1} t^{m}+k_{2} t^{2 m}
$$

where, the first term of the right-hand side is the Fickian contribution and the second term is associated with the relaxation release. The coefficient $m$ is the purely Fickian diffusion exponent. By rewriting and rearranging Equation (7), it is possible to calculate the percentage of $\mathrm{MH}$ release due to the Fickian mechanism, $F$, expressed as follows:

$$
F=\frac{1}{1+\frac{k_{2}}{k_{1}} t^{m}}
$$

Considering this expression, the ratio between relaxation $(R)$ and Fickian $(F)$ contributions is expressed as:

$$
\frac{R}{F}=\frac{k_{2}}{k_{1}} t^{m}
$$

If: (i) $\frac{R}{F}<1$, the Fickian diffusion dominates the process, (ii) $\frac{R}{F}=1$, the release involves both diffusion and relaxation/erosion process, and (iii) $\frac{R}{F}>1$, relaxation/erosion dominates the release process [76]. Our results show that the data fit well to the Peppas-Sahlin model $\left(R^{2}\right.$ SGF $=0.90$ and $R^{2}$ SIF $=0.91$ ), where $\frac{k_{2}}{k_{1}}$ was 0.18 and 0.074 for MH release in the SGF and SIF media, respectively; in addition, the $\frac{R}{F}$ ratio was $<1$ over the entire time range in both the biorelevant media studied. These results clearly show that despite the MH release being a coupling of Fickian diffusion and relaxation/erosion, the former is the dominant mechanism. In fact, the contribution of Fickian diffusion for $\mathrm{MH}$ release in SGF was more than $80 \%$ and the approximate contribution in the SIF was higher than $90 \%$.

\section{Conclusions}

A hybrid nanoantioxidant carrier based on porous silica nanoplatform with rosmarinic acid antioxidant immobilized on its surface was successfully development and characterized. Morin flavonoid was incorporated on the antioxidant nanocarrier by the impregnation/solvent evaporation technique with high drug loading $(23 \% w / w)$ compared to bare MSN $(9 \% w / w)$. The polyphenol-coated nanosystem maintains high antiradical activity of rosmarinic acid, showing the potential antioxidant activity of this nanosystem to protect different molecules from oxidation. Morin release profile was assessed in two biorelevant media, where the results show that the antioxidant nanosystem is capable of releasing more amount of morin at $\mathrm{pH} 6.8$ than at acidic $\mathrm{pH}$. This suggests that drug release will be favored at a more alkaline $\mathrm{pH}$, such as intestinal or colon segment, due to the repulsive force between the drug and the polyphenol layer on the surface. Kinetic studies show that the polyphenolic layer promotes a disturbance in the release mechanism compared to bare mesoporous silica nanoparticles, changing the Fickian diffusion to an anomalous non-Fickian transport. Nonetheless, the Fickian diffusion contribution is more than $80 \%$ of the release mechanism, suggesting that the polyphenolic surface could be tailored to favor of one or another release mechanism. Together, these results indicate the presence of an antioxidant nanocarrier for potential drug delivery application by incorporating it into a pharmaceutical formulation, which enhances the solubility of a drug and controls its release at the intestinal level. 
Author Contributions: Conceptualization, methodology, validation, formal analysis, investigation, data curation, project administration and writing-review and editing, F.A., G.G. and J.M.; software, F.A.; resources, writing-original draft preparation, visualization, supervision and funding acquisition F.A. and J.M. All authors have read and agreed to the published version of the manuscript.

Funding: This research was supported by grants from the Chilean CONICYT (CONICYT 21160932 and FONDECYT 1160757) and Universidad de Chile-PII2019.

Conflicts of Interest: The authors declare no conflict of interest.

\section{References}

1. Nasrollahzadeh, M.; Sajadi, S.M.; Sajjadi, M.; Issaabadi, Z. Chapter 4-Applications of nanotechnology in daily life. In Interface Science and Technology; Nasrollahzadeh, M., Sajadi, S.M., Sajjadi, M., Issaabadi, Z., Atarod, M., Eds.; Elsevier: Amsterdam, The Netherlands, 2019; Volume 28, pp. 113-143.

2. Bayda, S.; Adeel, M.; Tuccinardi, T.; Cordani, M.; Rizzolio, F. The history of nanoscience and nanotechnology: From chemical-physical applications to nanomedicine. Molecules 2020, 25, 112. [CrossRef]

3. He, X.; Deng, H.; Hwang, H.-M. The current application of nanotechnology in food and agriculture. J. Food Drug Anal. 2019, 27, 1-21. [CrossRef]

4. Zhang, R.X.; Li, J.; Zhang, T.; Amini, M.A.; He, C.; Lu, B.; Ahmed, T.; Lip, H.; Rauth, A.M.; Wu, X.Y. Importance of integrating nanotechnology with pharmacology and physiology for innovative drug delivery and therapy-An illustration with firsthand examples. Acta Pharmacol. Sin. 2018, 39, 825-844. [CrossRef]

5. Manzano, M.; Vallet-Regí, M. Mesoporous silica nanoparticles for drug delivery. Adv. Funct. Mater. 2020, 30 , 1902634. [CrossRef]

6. Vallet-Regí, M.; Colilla, M.; Izquierdo-Barba, I.; Manzano, M. Mesoporous silica nanoparticles for drug delivery: Current insights. Molecules 2017, 23, 47. [CrossRef]

7. Zhu, J.; Niu, Y.; Li, Y.; Gong, Y.; Shi, H.; Huo, Q.; Liu, Y.; Xu, Q. Stimuli-responsive delivery vehicles based on mesoporous silica nanoparticles: Recent advances and challenges. J. Mater. Chem. B 2017, 5, 1339-1352. [CrossRef]

8. Arriagada, F.; Nonell, S.; Morales, J. Silica-based nanosystems for therapeutic applications in the skin. Nanomedicine 2019, 14, 2243-2267. [CrossRef]

9. Kesse, S.; Boakye-Yiadom, K.O.; Ochete, B.O.; Opoku-Damoah, Y.; Akhtar, F.; Filli, M.S.; Asim Farooq, M.; Aquib, M.; Mily, M.; Joelle, B. Mesoporous silica nanomaterials: Versatile nanocarriers for cancer theranostics and drug and gene delivery. Pharmaceutics 2019, 11, 77. [CrossRef]

10. Gao, J.-K.; Zhang, Z.-J.; Jiang, Y.-J.; Chen, Y.; Gao, S.-F. Biomimetic-functionalized, tannic acid-templated mesoporous silica as a new support for immobilization of NHase. Molecules 2017, 22, 1597. [CrossRef]

11. Shao, D.; Li, M.; Wang, Z.; Zheng, X.; Lao, Y.-H.; Chang, Z.; Zhang, F.; Lu, M.; Yue, J.; Hu, H.; et al. Bioinspired diselenide-bridged mesoporous silica nanoparticles for dual-responsive protein delivery. Adv. Mater. 2018, 30, 1801198. [CrossRef]

12. Murugan, B.; Krishnan, U.M. Chemoresponsive smart mesoporous silica systems-An emerging paradigm for cancer therapy. Int. J. Pharm. 2018, 553, 310-326. [CrossRef]

13. Khalil, I.; Yehye, W.A.; Etxeberria, A.E.; Alhadi, A.A.; Dezfooli, S.M.; Julkapli, N.B.M.; Basirun, W.J.; Seyfoddin, A. Nanoantioxidants: Recent trends in antioxidant delivery applications. Antioxidants 2020, 9, 24. [CrossRef]

14. Sandhir, R.; Yadav, A.; Sunkaria, A.; Singhal, N. Nano-antioxidants: An emerging strategy for intervention against neurodegenerative conditions. Neurochem. Int. 2015, 89, 209-226. [CrossRef]

15. Sotiriou, G.A.; Blattmann, C.O.; Deligiannakis, Y. Nanoantioxidant-driven plasmon enhanced proton-coupled electron transfer. Nanoscale 2016, 8, 796-803. [CrossRef]

16. Deligiannakis, Y.; Sotiriou, G.A.; Pratsinis, S.E. Antioxidant and antiradical $\mathrm{SiO}_{2}$ nanoparticles covalently functionalized with gallic acid. ACS Appl. Mater. Interfaces 2012, 4, 6609-6617. [CrossRef]

17. Nunes, C.; Maricato, É.; Cunha, Â.; Nunes, A.; Silva, J.A.L.D.; Coimbra, M.A. Chitosan-caffeic acid-genipin films presenting enhanced antioxidant activity and stability in acidic media. Carbohydr. Polym. 2013, 91, 236-243. [CrossRef]

18. Ejima, H.; Richardson, J.J.; Caruso, F. Metal-phenolic networks as a versatile platform to engineer nanomaterials and biointerfaces. Nano Today 2017, 12, 136-148. [CrossRef] 
19. Massaro, M.; Riela, S.; Guernelli, S.; Parisi, F.; Lazzara, G.; Baschieri, A.; Valgimigli, L.; Amorati, R. A synergic nanoantioxidant based on covalently modified halloysite-trolox nanotubes with intra-lumen loaded quercetin. J. Mater. Chem. B 2016, 4, 2229-2241. [CrossRef]

20. Ebabe Elle, R.; Rahmani, S.; Lauret, C.; Morena, M.; Bidel, L.P.R.; Boulahtouf, A.; Balaguer, P.; Cristol, J.-P.; Durand, J.-O.; Charnay, C.; et al. Functionalized mesoporous silica nanoparticle with antioxidants as a new carrier that generates lower oxidative stress impact on cells. Mol. Pharm. 2016, 13, 2647-2660. [CrossRef]

21. Arriagada, F.; Günther, G.; Nos, J.; Nonell, S.; Olea-Azar, C.; Morales, J. Antioxidant nanomaterial based on core-shell silica nanospheres with surface-bound caffeic acid: A promising vehicle for oxidation-sensitive drugs. Nanomaterials 2019, 9, 214. [CrossRef]

22. Anna, C.; Paolo, C.; Alice, S.; Paolo, P. Morin: A promising natural drug. Curr. Med. Chem. 2016, 23, 774-791. [CrossRef]

23. Gopal, J.V. Morin hydrate: Botanical origin, pharmacological activity and its applications: A mini-review. Pharmacogn. J. 2013, 5, 123-126. [CrossRef]

24. Marković, Z.; Milenković, D.; Đorović, J.; Dimitrić Marković, J.M.; Stepanić, V.; Lučić, B.; Amić, D. PM6 and DFT study of free radical scavenging activity of morin. Food Chem. 2012, 134, 1754-1760. [CrossRef]

25. Kapoor, R.; Kakkar, P. Protective role of morin, a flavonoid, against high glucose induced oxidative stress mediated apoptosis in primary rat hepatocytes. PLoS ONE 2012, 7, e41663. [CrossRef]

26. Kempuraj, D.; Madhappan, B.; Christodoulou, S.; Boucher, W.; Cao, J.; Papadopoulou, N.; Cetrulo, C.L.; Theoharides, T.C. Flavonols inhibit proinflammatory mediator release, intracellular calcium ion levels and protein kinase $C$ theta phosphorylation in human mast cells. Br. J. Pharmacol. 2005, 145, 934-944. [CrossRef]

27. Lee, K.M.; Lee, Y.; Chun, H.J.; Kim, A.H.; Kim, J.Y.; Lee, J.Y.; Ishigami, A.; Lee, J. Neuroprotective and anti-inflammatory effects of morin in a murine model of Parkinson's disease. J. Neurosci. Res. 2016, 94, 865-878. [CrossRef]

28. Jin, H.; Lee, W.S.; Eun, S.Y.; Jung, J.H.; Park, H.-S.; Kim, G.; Choi, Y.H.; Ryu, C.H.; Jung, J.M.; Hong, S.C. Morin, a flavonoid from Moraceae, suppresses growth and invasion of the highly metastatic breast cancer cell line MDA-MB-231 partly through suppression of the Akt pathway. Int. J. Oncol. 2014, 45, 1629-1637. [CrossRef]

29. Jangid, A.K.; Pooja, D.; Kulhari, H. Determination of solubility, stability and degradation kinetics of morin hydrate in physiological solutions. RSC Adv. 2018, 8, 28836-28842. [CrossRef]

30. Zhang, J.; Li, J.; Ju, Y.; Fu, Y.; Gong, T.; Zhang, Z. Mechanism of enhanced oral absorption of morin by phospholipid complex based self-nanoemulsifying drug delivery system. Mol. Pharm. 2015, 12, 504-513. [CrossRef]

31. Li, J.; Yang, Y.; Ning, E.; Peng, Y.; Zhang, J. Mechanisms of poor oral bioavailability of flavonoid Morin in rats: From physicochemical to biopharmaceutical evaluations. Eur. J. Pharm. Sci. 2019, 128, 290-298. [CrossRef]

32. Fujimoto, A.; Masuda, T. Antioxidation mechanism of rosmarinic acid, identification of an unstable quinone derivative by the addition of odourless thiol. Food Chem. 2012, 132, 901-906. [CrossRef]

33. Petersen, M.; Simmonds, M.S.J. Rosmarinic acid. Phytochemistry 2003, 62, 121-125. [CrossRef]

34. Huang, N.; Hauck, C.; Yum, M.-Y.; Rizshsky, L.; Widrlechner, M.P.; McCoy, J.-A.; Murphy, P.A.; Dixon, P.M.; Nikolau, B.J.; Birt, D.F. Rosmarinic acid in prunella vulgaris ethanol extract inhibits lipopolysaccharide-induced prostaglandin E2 and nitric oxide in RAW 264.7 mouse macrophages. J. Agric. Food Chem. 2009, 57, 10579-10589. [CrossRef]

35. Ngo, Y.L.; Lau, C.H.; Chua, L.S. Review on rosmarinic acid extraction, fractionation and its anti-diabetic potential. Food Chem. Toxicol. 2018, 121, 687-700. [CrossRef]

36. Hamaguchi, T.; Ono, K.; Murase, A.; Yamada, M. Phenolic compounds prevent Alzheimer's pathology through different effects on the amyloid- $\beta$ aggregation pathway. Am. J. Pathol. 2009, 175, 2557-2565. [CrossRef]

37. Ugazio, E.; Gastaldi, L.; Brunella, V.; Scalarone, D.; Jadhav, S.A.; Oliaro-Bosso, S.; Zonari, D.; Berlier, G.; Miletto, I.; Sapino, S. Thermoresponsive mesoporous silica nanoparticles as a carrier for skin delivery of quercetin. Int. J. Pharm. 2016, 511, 446-454. [CrossRef]

38. Nairi, V.; Medda, S.; Piludu, M.; Casula, M.F.; Vallet-Regì, M.; Monduzzi, M.; Salis, A. Interactions between bovine serum albumin and mesoporous silica nanoparticles functionalized with biopolymers. Chem. Eng. J. 2018, 340, 42-50. [CrossRef] 
39. He, Y.; Liang, S.; Long, M.; Xu, H. Mesoporous silica nanoparticles as potential carriers for enhanced drug solubility of paclitaxel. Mater. Sci. Eng. C 2017, 78, 12-17. [CrossRef]

40. Liu, T.; Sui, X.; Zhang, R.; Yang, L.; Zu, Y.; Zhang, L.; Zhang, Y.; Zhang, Z. Application of ionic liquids based microwave-assisted simultaneous extraction of carnosic acid, rosmarinic acid and essential oil from Rosmarinus officinalis. J. Chromatogr. A 2011, 1218, 8480-8489. [CrossRef]

41. Brand-Williams, W.; Cuvelier, M.E.; Berset, C. Use of a free radical method to evaluate antioxidant activity. LWT Food Sci. Technol. 1995, 28, 25-30. [CrossRef]

42. Arriagada, F.; Günther, G.; Zabala, I.; Rubio-Retama, J.; Morales, J. Development and characterization of florfenicol-loaded BSA nanoparticles as controlled release carrier. AAPS Pharmscitech 2019, 20, 202. [CrossRef]

43. Boyd, B.J.; Bergström, C.A.S.; Vinarov, Z.; Kuentz, M.; Brouwers, J.; Augustijns, P.; Brandl, M.; Bernkop-Schnürch, A.; Shrestha, N.; Préat, V.; et al. Successful oral delivery of poorly water-soluble drugs both depends on the intraluminal behavior of drugs and of appropriate advanced drug delivery systems. Eur. J. Pharm. Sci. 2019, 137, 104967. [CrossRef]

44. Costa, P.; Lobo, J.M.S. Modeling and comparison of dissolution profiles. Eur. J. Pharm. Sci. 2001, 13, 123-133. [CrossRef]

45. Hermanson, G.T. Chapter 3-Zero-length crosslinkers. In Bioconjugate Techniques, 2nd ed.; Hermanson, G.T., Ed.; Academic Press: New York, NY, USA, 2008; pp. 213-233. [CrossRef]

46. Aytekin, A.O.; Morimura, S.; Kida, K. Synthesis of chitosan-caffeic acid derivatives and evaluation of their antioxidant activities. J. Biosci. Bioeng. 2011, 111, 212-216. [CrossRef]

47. Arriagada, F.; Correa, O.; Günther, G.; Nonell, S.; Mura, F.; Olea-Azar, C.; Morales, J. Morin flavonoid adsorbed on mesoporous silica, a novel antioxidant nanomaterial. PLoS ONE 2016, 11, e0164507. [CrossRef]

48. Barrett, D.G.; Sileika, T.S.; Messersmith, P.B. Molecular diversity in phenolic and polyphenolic precursors of tannin-inspired nanocoatings. Chem. Commun. 2014, 50, 7265-7268. [CrossRef]

49. Majoul, N.; Aouida, S.; Bessaïs, B. Progress of porous silicon APTES-functionalization by FTIR investigations. Appl. Surf. Sci. 2015, 331, 388-391. [CrossRef]

50. Lima, B.D.S.; Campos, C.D.A.; da Silva Santos, A.C.R.; Santos, V.C.N.; Trindade, G.D.G.G.; Shanmugam, S.; Pereira, E.W.M.; Marreto, R.N.; Duarte, M.C.; Almeida, J.R.G.D.S.; et al. Development of morin/hydroxypropyl- $\beta$-cyclodextrin inclusion complex: Enhancement of bioavailability, antihyperalgesic and anti-inflammatory effects. Food Chem. Toxicol. 2019, 126, 15-24. [CrossRef]

51. Ferraro, V.; Madureira, A.R.; Sarmento, B.; Gomes, A.; Pintado, M.E. Study of the interactions between rosmarinic acid and bovine milk whey protein $\alpha$-Lactalbumin, $\beta$-Lactoglobulin and Lactoferrin. Food Res. Int. 2015, 77, 450-459. [CrossRef]

52. Berlier, G.; Gastaldi, L.; Ugazio, E.; Miletto, I.; Iliade, P.; Sapino, S. Stabilization of quercetin flavonoid in MCM-41 mesoporous silica: Positive effect of surface functionalization. J. Colloid Interface Sci. 2013, 393, 109-118. [CrossRef]

53. Berlier, G.; Gastaldi, L.; Sapino, S.; Miletto, I.; Bottinelli, E.; Chirio, D.; Ugazio, E. MCM-41 as a useful vector for rutin topical formulations: Synthesis, characterization and testing. Int. J. Pharm. 2013, 457, 177-186. [CrossRef]

54. Schlipf, D.M.; Jones, C.A.; Armbruster, M.E.; Rushing, E.S.; Wooten, K.C.; Rankin, S.E.; Knutson, B.L. Flavonoid adsorption and stability on titania-functionalized silica nanoparticles. Colloids Surf. A Physicochem. Eng. Asp. 2015, 478, 15-21. [CrossRef]

55. Locatelli, M.; Gindro, R.; Travaglia, F.; Coïsson, J.-D.; Rinaldi, M.; Arlorio, M. Study of the DPPH-scavenging activity: Development of a free software for the correct interpretation of data. Food Chem. 2009, 114, 889-897. [CrossRef]

56. Zhu, F.; Asada, T.; Sato, A.; Koi, Y.; Nishiwaki, H.; Tamura, H. Rosmarinic acid extract for antioxidant, antiallergic, and $\alpha$-glucosidase inhibitory activities, isolated by supramolecular technique and solvent extraction from perilla leaves. J. Agric. Food Chem. 2014, 62, 885-892. [CrossRef]

57. Ayoob, I.; Lone, S.H.; Masood-ur-Rahman; Zargar, O.A.; Bashir, R.; Shakeel-u-Rehman; Khuroo, M.A.; Bhat, K.A. New semi-synthetic rosmarinic acid-based amide derivatives as effective antioxidants. ChemistrySelect 2017, 2, 10153-10156. [CrossRef]

58. Schaich, K.M.; Tian, X.; Xie, J. Reprint of "Hurdles and pitfalls in measuring antioxidant efficacy: A critical evaluation of ABTS, DPPH, and ORAC assays". J. Funct. Foods 2015, 18, 782-796. [CrossRef] 
59. Xie, J.; Schaich, K.M. Re-evaluation of the 2,2-diphenyl-1-picrylhydrazyl free radical (DPPH) assay for antioxidant activity. J. Agric. Food Chem. 2014, 62, 4251-4260. [CrossRef]

60. Spencer, J.P. Metabolism of tea flavonoids in the gastrointestinal tract. J. Nutr. 2003, 133, 3255S-3261S. [CrossRef]

61. Zhang, J.; Peng, Q.; Shi, S.; Zhang, Q.; Sun, X.; Gong, T.; Zhang, Z. Preparation, characterization, and in vivo evaluation of a self-nanoemulsifying drug delivery system (SNEDDS) loaded with morin-phospholipid complex. Int. J. Nanomed. 2011, 6, 3405.

62. Viitala, R.; Jokinen, M.; Rosenholm, J.B. Mechanistic studies on release of large and small molecules from biodegradable $\mathrm{SiO}_{2}$. Int. J. Pharm. 2007, 336, 382-390. [CrossRef]

63. Valgimigli, L.; Baschieri, A.; Amorati, R. Antioxidant activity of nanomaterials. J. Mater. Chem. B 2018, 6, 2036-2051. [CrossRef]

64. Li, J.; Wu, S.; Wu, C.; Qiu, L.; Zhu, G.; Cui, C.; Liu, Y.; Hou, W.; Wang, Y.; Zhang, L.; et al. Versatile surface engineering of porous nanomaterials with bioinspired polyphenol coatings for targeted and controlled drug delivery. Nanoscale 2016, 8, 8600-8606. [CrossRef]

65. Li, H.; Yan, G.; Wu, S.; Wang, Z.; Lam, K. Numerical simulation of controlled nifedipine release from chitosan microgels. J. Appl. Polym. Sci. 2004, 93, 1928-1937. [CrossRef]

66. Sánchez-Sánchez, Á.; Suárez-García, F.; Martínez-Alonso, A.; Tascón, J.M.D. pH-responsive ordered mesoporous carbons for controlled ibuprofen release. Carbon 2015, 94, 152-159. [CrossRef]

67. Peppas, N.A.; Sahlin, J.J. A simple equation for the description of solute release. III. Coupling of diffusion and relaxation. Int. J. Pharm. 1989, 57, 169-172. [CrossRef]

68. Tran, V.A.; Lee, S.-W. A prominent anchoring effect on the kinetic control of drug release from mesoporous silica nanoparticles (MSNs). J. Colloid Interface Sci. 2018, 510, 345-356. [CrossRef]

69. 5-Mathematical models of drug release. In Strategies to Modify the Drug Release from Pharmaceutical Systems; Bruschi, M.L. (Ed.) Woodhead Publishing: Cambridge, UK, 2015; pp. 63-86. [CrossRef]

70. Yamada, H.; Urata, C.; Aoyama, Y.; Osada, S.; Yamauchi, Y.; Kuroda, K. Preparation of colloidal mesoporous silica nanoparticles with different diameters and their unique degradation behavior in static aqueous systems. Chem. Mater. 2012, 24, 1462-1471. [CrossRef]

71. Chen, K.; Zhang, J.; Gu, H. Dissolution from inside: A unique degradation behaviour of core-shell magnetic mesoporous silica nanoparticles and the effect of polyethyleneimine coating. J. Mater. Chem. 2012, 22, 22005-22012. [CrossRef]

72. Mijowska, E.; Cendrowski, K.; Barylak, M.; Konicki, W. Sandwich-like mesoporous silica flakes for anticancer drug transport-Synthesis, characterization and kinetics release study. Colloids Surf. B Biointerfaces 2015, 136, 119-125. [CrossRef]

73. Braun, K.; Pochert, A.; Beck, M.; Fiedler, R.; Gruber, J.; Lindén, M. Dissolution kinetics of mesoporous silica nanoparticles in different simulated body fluids. J. Sol-Gel Sci. Technol. 2016, 79, 319-327. [CrossRef]

74. Lee, H.; Dellatore, S.M.; Miller, W.M.; Messersmith, P.B. Mussel-inspired surface chemistry for multifunctional coatings. Science 2007, 318, 426-430. [CrossRef]

75. Sileika, T.S.; Barrett, D.G.; Zhang, R.; Lau, K.H.A.; Messersmith, P.B. Colorless multifunctional coatings inspired by polyphenols found in tea, chocolate, and wine. Angew. Chem. Int. Ed. 2013, 52, 10766-10770. [CrossRef]

76. Unagolla, J.M.; Jayasuriya, A.C. Drug transport mechanisms and in vitro release kinetics of vancomycin encapsulated chitosan-alginate polyelectrolyte microparticles as a controlled drug delivery system. Eur. J. Pharm. Sci. 2018, 114, 199-209. [CrossRef]

(C) 2020 by the authors. Licensee MDPI, Basel, Switzerland. This article is an open access article distributed under the terms and conditions of the Creative Commons Attribution (CC BY) license (http://creativecommons.org/licenses/by/4.0/). 